\title{
Development of Paracetamol-Caffeine co-crystals to improve compressional, formulation and in-vivo performance
}

Sumera Latif ${ }^{a}$, Nasir Abbas ${ }^{a^{*}}$, Amjad Hussain ${ }^{a}$, Muhammad Sohail Arshad ${ }^{b}$, Nadeem Irfan Bukhari ${ }^{\mathrm{a}}$, Hafsa Afzal ${ }^{\mathrm{a}}$, Sualeha Riffat ${ }^{\mathrm{c}}$, Zeeshan Ahmad ${ }^{\mathrm{d}}$
a. University College of Pharmacy, University of the Punjab, Lahore, Pakistan
b. Department of Pharmacy, Bahaudin Zakiria University, Multan, Pakistan
c. University of Veterinary and Animal Sciences, Lahore, Pakistan
d. Leicester School of Pharmacy, De Montfort University, Leicester, UK

*Correspondence: nasirabbas77@gmail.com 


\section{Development of Paracetamol-Caffeine co-crystals to improve compressional, formulation and in-vivo performance}

\section{ABSTRACT}

Paracetamol, a frequently used antipyretic and analgesic drug, has poor compression moldability owing to its low plasticity. In this study, new co-crystals of paracetamol (PCM) with caffeine (as a co-former) were prepared and delineated. Co-crystals exhibited improved compaction and mechanical behavior. A screening study was performed by utilizing a number of methods namely dry grinding, liquid assisted grinding (LAG), solvent evaporation (SE) and anti-solvent addition using various weight ratios of starting materials. LAG and SE were found successful in the screening study. Powders at 1:1 and 2:1 weight ratio of PCM/CAF by LAG and SE respectively resulted in the formation of co-crystals. Samples were characterized by PXRD, DSC and ATRFTIR techniques. Compressional properties of PCM and developed co-crystals were analyzed by in-die heckle model. Mean yield pressure (Py), an inverse measure of plasticity, obtained from the heckle plots decreased significantly $(p<0.05)$ for co-crystals than pure drug. Intrinsic dissolution profile of co-crystals showed up to 2.84 fold faster dissolution than PCM and physical mixtures in phosphate buffer $\mathrm{pH} 6.8$ at $37{ }^{\circ} \mathrm{C}$. In addition co-crystals formulated into tablets by direct compression method showed better mechanical properties like hardness and tensile strength. In vitro dissolution studies on tablets also showed enhanced dissolution profiles ( 90-97\%) in comparison to the tablets of PCM prepared by direct compression $(\sim 55 \%)$ and wet granulation $(\sim 85 \%)$ methods. In a single dose sheep model study co-crystals showed up to two fold increase in AUC and $\mathrm{C}_{\max }$. A significant $(p<0.05)$ decrease in clearance as compared to pure drug was also recorded. In conclusion new co-crystals of PCM were successfully prepared with improved tabletability in-vitro and in-vivo profile. Enhancement in AUC and $\mathrm{C}_{\max }$ of PCM by cocrystallisation might suggest the dose reduction and avoidance of side effects.

Key Words: Paracetamol, Caffeine, Co-crystals, Intrinsic dissolution rate, Tabletability, In-vitro dissolution, Bioavailability

\section{INTRODUCTION}

The successful development of a pharmaceutical dosage form requires adequate physical and mechanical properties of an active pharmaceutical ingredient (API). However, APIs with limited physical properties are becoming prevalent during the research and development process in 
pharmaceutical companies. Some compounds have less aqueous solubility and slow in vivo dissolution rate especially those belonging to the BCS class II (Low solubility and high permeability) and IV (Low solubility and low permeability) (1-4) others have high hygroscopicity and exhibit poor compaction properties. The properties e.g. solubility and dissolution rate are directly related to the bioavailability of the drugs, particularly when delivered via oral route $(5,6)$. On the other hand poor mechanical properties cause difficulties in the processing e.g. milling and compaction of a solid dosage form. Advancement in the pharmaceutical sciences has resulted in the establishment of a number of approaches to address these issues. These approaches include reduction of particle size (7), salt formation (8), prodrug formation, complexation $(9,10)$ and liposomes for the delivery of lipophilic drugs (11). Although these techniques are very effective in enhancing the oral bioavailability and processing properties of drugs, the success of these approaches is dependent on the specific physicochemical nature of the compound being studied. For example salt formation which is only limited to ionizable compounds, complexation with disadvantages like low extent of interaction with complexing agent, increased toxicity, high cost and precipitation, prodrug which may not be adequately delivered at the site of action and particle size reduction limited by particle size induction and amorphization.

In recent years advancement in crystal engineering techniques like co-crystallization provides an alternative approach for improving various physicochemical properties of drug substances (1215). Control of molecular packing within a crystal structure/lattice produces a solid that shows desirable characteristics including chemical stability (16, 17, 18), solid state stability (19), dissolution rate and bioavailability $(20,21)$, and compaction behavior (22-24). Furthermore, cocrystals may have an advantage over the high-energy crystal forms of superior thermodynamic stability in the solid-state $(6,25)$. Therefore the interest in the co-crystallization has increased considerably over the past few years.

Pharmaceutical co-crystals are defined as supramolecular entities consisting of two or more molecular moieties held together by weak non-covalent and non-ionic intermolecular interactions (e.g. hydrogen bonding, $p$ stacking, and VanderWaals forces) in which at least one or both constituents are active pharmaceutical agents i.e. two different molecules in a single crystalline lattice $(26,27)$. Drugs having the ability to form hydrogen bonding with co-formers are considered as potential candidates for co-crystallization technique. Co-crystals of many pharmaceutical drugs 
are reported in literature e.g. carbamazepine, indomethacin, furosemide and piroxicam etc. (28). Recently various novel methods for the efficient production and monitoring of co-crystals have been proposed (29).

Paracetamol (PCM) is widely used analgesic and antipyretic agent. It has low aqueous solubility and poor mechanical and compressional properties and hence has poor tabletability. Many studies have reported the problem of high capping which is related to stiff nature and a relatively high elastic deformation of PCM (30). Due to these reasons, PCM tablets are being prepared using large amount of a binder to prevent chipping and disintegration of tablet dosage form (24). Similarly a change in crystal structure e.g. polymorphsim or crystal habit has been shown to improve tableting properties of PCM (31). Nevertheless lack of acidic or basic functional groups and presence of both proton donors (phenolic $\mathrm{O}-\mathrm{H}$ and the amidic $\mathrm{N}-\mathrm{H}$ groups) and acceptor (the amidic oxygen atom) make PCM a good model drug for co-crystal study. Caffeine (CAF) has already been successfully utilized as a co-former, and is a generally recognized as safe (GRAS) status compound. It has functional groups (keto-amide groups and basic nitrogen) which make it as a good candidate to form intermolecular hydrogen bonds in co-crystal formation (Figure 1) (22). Furthermore PCM is also available as fixed dose combination with caffeine to synergise the analgesic effect of PCM.

In the present work attempts were made to produce co-crystals of PCM with CAF as a co-former, these co-crystals has not been reported previously. Four different co-crystallisation methods were employed in the screening studies, with the aim to improve the compressional, mechanical behaviour and dissolution profile of the drug. Prepared co-crystals were evaluated for intrinsic dissolution rate and compaction behavior. Previously mechanical properties of co-crystals were determined by measuring the tensile strength only, however our study involves the heckle analysis, which give more thorough insight about the plasticity. Pharmacokinetic studies of newly formed co-crystals were also performed on sheep model in order to highlight the potential increase in oral bioavailability. Literature review has shown that only a few bioavailability studies have been reported for the co-crystals $(19,20)$. To our knowledge, this is the first bioavailability study done one the PCM co-crystals. Lastly tablet formulations prepared from these co-crystals were also assessed for the pharmacotechnical properties. 
Place figure 1 here

\section{EXPERIMENTAL}

\section{Materials and Methods}

PCM and CAF were obtained as gift samples from UNEXO Pharmaceuticals and Avicel PH 102 and magnesium stearate from Remington Pharmaceuticals, Lahore, Pakistan and were used as received. All organic solvents used were of HPLC or analytical grade. A phosphate buffer at $\mathrm{pH}$ 6.8 was prepared by mixing $250 \mathrm{ml}$ of $\mathrm{KH}_{2} \mathrm{PO}_{4}(0.2 \mathrm{M})$ and $112 \mathrm{ml}$ of $\mathrm{NaOH}(0.2 \mathrm{M})$ with final dilution to $1 \mathrm{~L}$ with distilled water.

\section{Screening of co- crystals}

Various methods like mechanochemical (dry grinding, liquid assisted grinding (LAG)), solvent evaporation (SE) and anti-solvent addition (ASA) were used for the formation of co-crystals of PCM with CAF.

\section{Dry and liquid assisted grinding}

PCM and CAF in three different weight ratios $(1: 1,1: 2 \& 2: 1)$ were co ground in a mortor and pestle without and with small amount of liquid ( $\sim 50 \mu \mathrm{L}$ for each of $100 \mathrm{mg}$ of PCM and CAF) for 30 minutes. Solvents used were V/V mixture of methanol \& ethanol (1:1\&1:2) and pure acetone. The powder was collected in tight containers and stored at room temperature.

\section{Solvent evaporation method}

PCM and CAF in three different weight ratios $(1: 1,1: 2 \& 2: 1)$ were dissolved in a V/V mixture of methanol \& ethanol (1:1 \&1:2), mixture of distilled water \& ethanol $(1: 1,1: 2)$ and pure acetone with aid of slight heating until a clear solution obtained. Each of these solutions was then filtered and left for evaporation at room temperature. The solid crystals obtained were collected in a tight container for further analysis and stored at room temperature. 


\section{Anti-solvent addition}

Excess amount of PCM and CAF (1:1, 1:2 \& 2:1 weight ratio) were added to $5 \mathrm{ml}$ of methanol and acetone separately to make turbid solutions, stirred for 15 minutes and filtered through Whatman filter paper. Distilled water (2 ml) (as an anti-solvent (32)) was added to the filtrate to induce precipitation. Samples were then centrifuged at $3000 \mathrm{rpm}$ for 20 minutes to allow solids to deposit out.

\section{Characterization}

The pure drugs and co-crystals prepared by the above methods were investigated by DSC, PXRD, ATR-FTIR and Intrinsic dissolution rate (IDR) studies.

\section{Differential scanning calorimetry (DSC)}

DSC studies were performed using a TA instrument (model Q 600, USA). Samples (2-5 mg) contained in alumina pan with an empty pan as a reference were analyzed from room temperature $\left(25 \pm 2{ }^{\circ} \mathrm{C}\right)$ to $300{ }^{\circ} \mathrm{C}$ with a constant heating rate $\left(10{ }^{\circ} \mathrm{C} / \mathrm{min}\right)$ under a nitrogen purge $(100 \mathrm{ml} / \mathrm{min})$.

\section{Powder X-Ray Diffraction (PXRD)}

PXRD patterns were obtained for PCM, CAF and co-crystals synthesized by various methods. Powder samples were used as such without any pre treatment. PXRD data were collected on a Pan Analytical diffractometer XPERT-PRO (operating at $40 \mathrm{kV}, 40 \mathrm{~mA})$, using $\mathrm{Cu}-\mathrm{K} \alpha$ radiation $(\lambda=$ $1.5418 \AA$ ) with a position sensitive detector. Diffraction data were collected in the range $2 \theta=5$ $30^{\circ}$ with a step size of $0.02^{\circ}$.

\section{ATR-FTIR spectroscopy}

Fourier Transform Infrared (FTIR) spectra were recorded for the PCM, CAF and synthesized cocrystals using FTIR spectrophotometer (Alpha-P Bruker, Germany) equipped with an ATR unit across the range of $4000-400 \mathrm{~cm}^{-1}$.

Scanning Electron Microscopy (SEM) 
Powder samples were photographed by ZEISS EVO HD 15 scanning electron microscope (Carl Zeiss, NTS Ltd. Cambridge, UK) with auto imaging system. The samples were mounted on carbon adhesive tape fixed on aluminium stubs (Agar Scientific Ltd., Stansted, UK), flushed with air and photographed at the voltage of $2 \mathrm{KV}$ for 25 seconds.

\section{Drug content analysis}

A stock solution containing $1 \mathrm{mg} / \mathrm{mL}$ of pure drug was prepared by dissolving $100 \mathrm{mg}$ of PCM in $100 \mathrm{~mL}$ of phosphate buffer ( $\mathrm{pH}$ 6.8) using a volumetric flask. The standard stock solution was further diluted to obtain a working standard solution of $100 \mu \mathrm{g} / \mathrm{ml}$. Working standard solution was then diluted with phosphate buffer ( $\mathrm{pH}$ 6.8) to obtain a series of solutions with the concentration range of $2-16 \mu \mathrm{g} / \mathrm{ml}$. A calibration curve for PCM was prepared by measuring the absorbance at the $\lambda_{\max }$ of $243 \mathrm{~nm}$. Statistical parameters like slope, intercept and coefficient of correlation were determined to model the linearity of absorbance data.

For drug content analysis, each of the co-crystal samples was accurately weighed (10 mg) and dissolved in phosphate buffer $\mathrm{pH} 6.8$ to give final concentration of $10 \mu \mathrm{g} / \mathrm{ml}$. The drug content was calculated from the calibration curve.

\section{Intrinsic dissolution studies}

The intrinsic dissolution rate (IDR) of pure drug, physical mixtures and co-crystals was determined by rotating disc method using a constant surface area of $13 \mathrm{~mm}$ in diameter. Discs were prepared by compressing $300 \mathrm{mg}$ of powder samples by a hydraulic press (Carver, USA) at a pressure of 5000 psi for 60-90 seconds. The compacts were coated with hard paraffin leaving a surface available for dissolution $(33,34)$ and then placed to the base of the dissolution vessel.

The dissolution studies, performed in triplicate, were carried out in phosphate buffer $\mathrm{pH} 6.8$ (volume: $500 \mathrm{ml}$, temperature: $37^{\circ} \mathrm{C}$ ) in a paddle apparatus (Apparatus 2, USP) at a rotation speed of $50 \mathrm{rpm}$. Aliquots (5 ml) were withdrawn at time intervals of 2, 4, 6, 8, 10, 14, 18 and $22 \mathrm{~min}$. Samples were filtered through $0.45 \mu \mathrm{m}$ filters and analyzed at $243 \mathrm{~nm}$. Dissolution medium was replenished with the same volume $(5 \mathrm{ml})$ of blank (phosphate buffer $\mathrm{pH} 6.8$ ) in order to maintain 
the sink conditions. IDR was determined by plotting the cumulative amount of drug dissolved per surface area $\left(\mathrm{mg} / \mathrm{cm}^{2}\right)$ versus time $(\mathrm{min})$.

\section{Compressional behavior}

In-die heckle model (35) for powder deformation under pressure (equation 1) was used to study the compressional behavior of pure PCM and prepared co-crystals powders. Bulk density of each powder was determined by the standard method. Each of the material (300 mg) was individually compacted under compressional force between 2 and $14 \mathrm{MPa}$ using a hydraulic press (Carver, USA) equipped with flat faced dies $13 \mathrm{~mm}$ in diameter. Volume reduction was measured at each compaction pressure used.

$$
\frac{\mathrm{dD}}{\mathrm{dP}}=\mathrm{K}(1-\mathrm{D}) \quad \text { Eq. } 1
$$

Where, $\mathrm{D}$ is the relative density of the compact at applied pressure $\mathrm{P}$, and the constant $\mathrm{K}$ is a measure of the plasticity of the compressed material. Integration of equation 1 gives equation 2.

$$
\frac{\operatorname{Ln}(1)}{(1-\mathrm{D})}=\mathrm{KP}+\mathrm{A} \quad \text { Eq. } 2
$$

A plot was drawn between Ln (1)/1-D and compaction pressure (P) for each powder. A is the intercept of the extrapolated linear region of the curve. Mean yield pressure (P y), a measure of the material's resistance for deformation (36), was obtained from the reciprocal of the slope (K) of the linear portion of the heckle plot. The higher the value of slope $\mathrm{K}$ is, more plastic is the material.

\section{Preparation of Tablets}

Direct compression method was used to prepare tablets from all co-crystal powders. For this purpose co-crystal equivalent to $250 \mathrm{mg}$ of PCM was blended with Avicel PH 102 (20\% of the weight of co-crystal) and magnesium stearate $(0.5 \%$ of the weight of co-crystal) for about $15 \mathrm{~min}$. The mass was then compressed using a hydraulic press fitted with $13 \mathrm{~mm}$ diameter die. As pure PCM cannot be directly compressed due to poor compressional properties, it was moistened with small amount of water and then dried at $50{ }^{\circ} \mathrm{C}$ for 10 minutes to induce plasticity and then compacted (F1). Tablets from physical mixtures (1:1 \& 2:1 by weight ratio of PCM and CAF) were prepared following the same procedure. Tablets of pure PCM (F2) (250 mg equivalent) were 
also prepared by the standard wet granulation (WG) method using starch paste (10\% of the weight of PCM) as a binder and dry starch as disintegrating agent (10\% of the weight of PCM).

\section{Evaluation of tablets}

All the prepared tablets were evaluated for hardness, tensile strength, disintegration time and in vitro dissolution study. Hardness was determined using Pharmatron Multitest $50 \mathrm{H}$ and expressed in newton. Tensile strength, $\sigma$, in MPa was determined by diametral compression test (37) and calculated by using equation 3 .

$$
\sigma=\frac{2 \mathrm{~F}}{10^{6} \pi \mathrm{DT}} \quad \text { Eq. } 3
$$

Where $\mathrm{F}$ is the breaking force $(\mathrm{N}), \mathrm{D}$ is the tablet diameter $(\mathrm{m})$, and $\mathrm{T}$ is the thickness of tablet (m). Disintegration test was carried out by tablet disintegration test apparatus using distilled water at $37^{\circ} \mathrm{C}$.

\section{In- vitro dissolution study}

Dissolution studies for all prepared tablets were performed using phosphate buffer $\mathrm{pH} 6.8$ (volume: $900 \mathrm{ml}$, temperature: $37^{\circ} \mathrm{C}$ ) as a dissolution medium in a paddle apparatus (Apparatus 2, USP) at a rotation speed of $50 \mathrm{rpm}$. Aliquot $(5 \mathrm{ml})$ was withdrawn at time intervals of 3, 6, 9, 12, 17, 22, 27 and 32 minutes and replaced with fresh dissolution medium in order to maintain the sink conditions. These samples were analyzed for PCM concentration by UV Visible spectrophotometer at $243 \mathrm{~nm}$. All the measurements were done in triplicate. Percent drug release

was determined from the calibration curve $\left(\mathrm{R}^{2}=0.996\right)$. The drug release data was also fitted to various kinetic models such as zero order, first order, and Higuchi, Korsmeyer-Peppas and HixonCrowell model using DD solver (38).

\section{In-vivo studies in sheep}


An in-vivo study was conducted in sheep model in order assess the pharmacokinetic profiles of pure PCM and co-crystals. Sheep model was selected for preclinical evaluation owing to its easy handling, more clinically precise and relevant dose alignment. Moreover collection of multiple samples per animal is possible without adding risk to animal's life. The protocols used for this studies were approved by animal ethical committee, University College of Pharmacy, University of the Punjab, Lahore, Pakistan (ref no. AEC/PUCP/1047A). Three groups $(n=6)$ of sheep were orally administered at a dose of $30 \mathrm{mg} / \mathrm{kg}$ body weight with pure PCM and equivalent co-crystals in gelatin capsules after an overnight fast. Collection of blood samples $(3 \mathrm{ml})$ were undertaken from jugular vein in heparinized tubes at $0,0.25,0.5,1,1.5,2,4,6,8$ and 10 hour intervals postdose. From the whole blood, plasma was separated by centrifugation at $3500 \mathrm{rpm}$ for 5 minutes and supernatant was collected in Eppendorf tube and stored at $-20{ }^{\circ} \mathrm{C}$ for further studies.

For drug analysis, to $1 \mathrm{ml}$ of plasma, $60 \mu \mathrm{l}$ of $50 \%$ perchloric acid was added. This mixture was vortexed for 5 minutes and centrifuged at $13500 \mathrm{rpm}$ for 15 minutes. Supernatant was filtered using $0.22 \mu \mathrm{m}$ syringe filter. $50 \mu \mathrm{l}$ of clear filtrate was injected into the HPLC with a run time of 10 minutes and drug content was analyzed with a previously reported method (39). The HPLC system (Shimadzu 20A, Japan) was equipped with a LC-20AT VP pump, a SIL-20AC HT auto sampler, SPD-M20A detector (photodiode array), CTO 20 AC column oven, CBM 20A controller unit and a reversed phase symmetry C18 (4.6 x $250 \mathrm{~mm}, 5-\mu \mathrm{m}$ particle-size $)$ column. The mobile phase was composed of water, methanol, and acetonitrile $(80: 10: 10, \mathrm{v}: \mathrm{v}: \mathrm{v})$, filtered through a 0.45 membrane filter and was delivered at a flow rate of $1 \mathrm{ml} / \mathrm{min}$. The analysis was carried out under isocratic conditions maintaining column temperature at $40^{\circ} \mathrm{C}$. A photodiode array detector set at $245 \mathrm{~nm}$ was used for recording chromatograms. Calibration curve $\left(\mathrm{R}^{2}=0.9974\right)$ prepared for PCM was based on peak area measurements of standard solutions and spiked plasma samples for concentrations of $0.1,0.5,1.0,5.0,10.0$, and $15.0 \mu \mathrm{g} / \mathrm{ml}$. The limits of detection and quantification were 0.03 and $0.1 \mu \mathrm{g} / \mathrm{ml}$ respectively.

The maximum plasma concentration $\left(\mathrm{C}_{\max }\right)$ and the time to reach maximum concentration $\left(\mathrm{T}_{\max }\right)$ were directly obtained from the plasma concentration versus time curves. Pharmacokinetic parameters including area under the curve (AUC), area under the first moment curve (AUMC), mean residence time (MRT), plasma clearance (CL), apparent volume of distribution (Vd), 
elimination rate constant $\left(\mathrm{K}_{\mathrm{el}}\right)$ and half life $\left(\mathrm{t}_{1 / 2}\right)$ were calculated using non-compartmental analysis and PK solver pharmacokinetic programme (40).

Statistical analysis was conducted by SPSS (IBM SPSS Statistics 22). Statistical data was obtained by using one way ANOVA and post hoc comparisons. Statistical significance was considered when $p<0.05$.

\section{RESULTS AND DISCUSSION}

Co-crystal screening was carried out by four different methods as described in Table 1. Formation of co-crystals were recorded by difference in melting points and PXRD patterns from the individual components. PCM-CAF co crystals were successfully prepared by LAG and SE methods. In LAG, mixtures of PCM and CAF at weight ratio 1:1 with solvents S1, S2 and S3 were resulted in co-crystals (PXRD pattern were different from either of the two starting materials, Figure 2). In SE method the solution of PCM and CAF in weight ratio 2:1 using solvent systems (S1 and S2) resulted in formation of co-crystals. All the other mixtures/solutions in the screening study produced intact crystals of the individual components i.e. PCM and CAF.

Place table 1 here

Characterization of newly formed co-crystals was performed using three different techniques namely PXRD, DSC and FTIR. PXRD patterns of co-crystals were compared with three polymorphs of PCM (denoted as Form I, II and III) and two polymorphs of CAF (denoted as Form I and II) in Figure 2. Characteristics peaks of all the polymorphs of PCM and CAF were not observed in the patterns of co-crystals. Moreover new peaks were emerged at $2 \theta$ value of $8.41^{\circ}$, $9.06^{\circ}, 11.39^{\circ}$ and $17.66^{\circ}$ suggesting the formation of a new phase. The difference in the intensity of major peaks in PXRD parents of co-crystals (Figure 2) were due to preferred orientation effect (instrument used had a flat sample stage), which may be due to dissimilarity in the habit of particles produced by two different methods. A, B and C samples were prepared by the liquid assisted grinding (LAG) technique, where grinding resulted in fine powders. However samples D and E were prepared by solvent evaporation (SE) technique. Recrystallization in this case resulted in small crystallites which create problem in the packing of samples for PXRD analysis. DSC data also showed that the resultant powders are new phases as the melting point of co-crystals are 
significantly different from all the polymorphs of starting materials. However, precise stoichiometric and structural description of these co-crystals needs further analysis by single crystal XRD, which may form the subject of our future studies..

DSC curves of newly formed co-crystals and pure PCM (identified as form I) and CAF are shown in Figure 3. PCM sample showed a sharp endothermic peak with mid point at $172.37{ }^{\circ} \mathrm{C}$ representing the melting of PCM form I. Although not evident in this study, paracetamol also exist as polymorphs II and III. Form II has melting point at $160^{\circ} \mathrm{C}$, while Form III is most unstable form and converts back to form I. CAF thermogram showed two endothermic peaks with mid points at $160.33{ }^{\circ} \mathrm{C}$ and $231.08{ }^{\circ} \mathrm{C}$ representing melting of its polymorphic forms i.e. form II and I, respectively. DSC curves of co-crystals prepared by the LAG and SE techniques showed endothermic peaks with onset temperatures $\sim 130{ }^{\circ} \mathrm{C}$ and $133^{\circ} \mathrm{C}$ respectively (Table 2), which are lower than the individual components (PCM and CAF) and all their polymorphs. However sample D showed two overlapping peaks which indicate lack of phase purity. With small exceptions, it can be presumed that the co-crystals formation resulted in increased entropy evident as a broad endothermic peak at temperatures lower than the individual counterparts.

Figure 4 shows comparison of FTIR spectra of prepared co-crystals with PCM and its physical mixture with caffeine in the functional group region of $3000-3400 \mathrm{~cm}^{-1}$. For PCM, peaks for N-H amide stretch and phenolic $\mathrm{OH}$ stretch were observed at 3323 and $3108 \mathrm{~cm}^{-1}$ respectively. These functional groups are involved in the hydrogen bonding of PCM molecules in the crystal structure (41). Overall FTIR spectra of co-crystals in the range 400 to $3500 \mathrm{~cm}^{-1}$ show almost similar pattern as of PCM, however a shift in the above described bands (i.e. to $3316 \mathrm{~cm}^{-1}$ and $3104 \mathrm{~cm}^{-1}$ respectively) was observed. This indicates a slight change in the hydrogen bonding pattern of PCM in the form of co-crystal. These shifts were not observed for physical mixture.

Place table 2 here

Place figure 2, 3 and 4 here

Intrinsic dissolution rate (IDR) 
Intrinsic dissolution rate (IDR) method was employed as it affords advantages over other powder dissolution methods because the exposed area of the disk is constant and thus dissolution variability can be minimized. Intrinsic dissolution profiles of the prepared co-crystals compared with pure drug are shown in Figure 5. IDR of PCM recorded in phosphate buffer pH 6.8 was 5.06 $\mathrm{mg} / \mathrm{cm}^{2}$-min, while for co-crystals A, B, C, D and E was 8.72, 9.53, 12.23, 11.11 and 14.40 $\mathrm{mg} / \mathrm{cm}^{2}$-min respectively. Based on the initial dissolution rate, co-crystals A, B, C, D and E showed $1.72,1.88,2.42,2.19$ and 2.84 fold increase in dissolution rate. In comparison the physical mixture showed almost same IDR $\left(5.5 \mathrm{mg} / \mathrm{cm}^{2}\right.$-min) as of the pure drug. This high dissolution rate might indicate the stability of prepared co-crystals to prevent dissociation of drug and co-former from each other and achieve the solubility and dissolution advantages of co-crystals (42).

IDR is the dissolution rate that is greatly influenced by the intrinsic factors especially the crystal habit and particle size distribution. The variation among the IDR values of co-crystals can be explained by the fact that the powders prepared by the two different methods (LAG and SE) have different particle size distribution and shapes. This is evident from the SEM images of these samples as shown in Figure 6. Mechanochemical method (LAG) produced fine powders with high compressibility index $(\sim 31.12 \%)$. On the other hand the powder samples prepared by SE method show larger particles with low compressibility index value of $\sim 20.55 \%$. Owing to this fact more compact IDR discs were prepared from LAG samples which resulted in lower values of IDR as compared to samples of SE. This is also evident from the higher breaking force (hardness) of the tablet formulations prepared from A, B and C samples as compared to D and E samples (Table 3).

Place figure 5 here

Place figure 6 here

\section{Compressional and mechanical properties}

Poor compressibility of PCM due to low plasticity is always a problem for the formulation scientists. To overcome this problem, PCM is normally tableted by wet granulation (WG) method, which is a time consuming and laborious procedure and required a large amount of excipients to be added to the formulation. Development of crystal structures, which provide large interparticulate bonding area and plasticity, has been proposed as a strategy to improve the tensile 
strength of materials (43). In the present study heckle plots were drawn for pure PCM and cocrystals powders to assess the plastic behavior induced by co-crystallization (Figure 7). Co-crystals showed improved compaction and hence high plasticity. This was shown by low Py (mean yield pressure) value for co-crystals as compared to pure drug. Py recorded for PCM was 133.33 MPa. The same parameter for formed co-crystals A, B, C, D and E was significantly decreased i-e. 33.03, 80, 28.65, 33.03 and $47.62 \mathrm{MPa}$ respectively. The ranking of the Py values was $\mathrm{C}<\mathrm{A} \& \mathrm{D}<\mathrm{E}<\mathrm{B}<\mathrm{PCM}$ (Table 3). These values were calculated from the region of heckle plots showing the highest correlation coefficient for linearity of $>0.989$ for all the powder samples. The yield pressure, $\mathrm{Py}$, is the stress at which particle deformation is initiated reflecting the deformation of the particles during compression (44). Difference in compression properties among co-crystals produced by LAG and SE is due to dissimilar crystal plasticity which may result from unique molecular packing features in the respective crystal lattices. Mechanochemically synthesized cocrystals are more plastic and have high tensile strength as evident from their low mean yield pressure (Py) value (33.03 \& 28.65). Previous literature also confirms mechanochemical synthesis as an efficient approach to produce plastic and compressible forms of PCM using oxalic acid, phenazine, theophylline and naphthalene as coformers (24).

Place figure 7 here

Results from the compression data indicate that co-crystals can easily be formulated, by direct compression with adequate hardness to the tablet dosage form without adding any binder. The tensile strength higher than $3 \mathrm{MPa}$ was exhibited by tablets based on co-crystals prepared by LAG (FA, FB and FC) while the tablets based on co-crystals prepared by SE were in the vicinity of $>1.8$ MPa (Table 3). This suggests that mechanochemical methods of co-crystallization are more suitable to improve the pharmacotechnical properties of PCM.

Place table 3 here

\section{In- Vitro drug release study of Tablets}

Various tablet formulations prepared from pure drug, physical mixtures and co-crystals were subjected to the in vitro dissolution studies for the release of PCM. Direct compression method was employed for the co-crystals formulations (FA, FB, FC, FD and FE). However for pure drug, 
both liquid assisted direct compression (F1) and wet granulation method (F2) were used. Figure 8 shows comparison of dissolution profiles of these formulations. All the co-crystals formulations showed 90 - $97 \%$ release within $20 \mathrm{~min}$. This was greater than corresponding physical mixtures $(55 \%), \mathrm{F} 1(72 \%)$ and F2 (85\%).

As already explained before that the LAG method of co-crystallization produce powders with a large surface area so mechanochemical synthesis based formulations were expected to give better dissolution profiles as compared to SE based formulations. This can also be confirmed by SEM results. Furthermore, grinding in the presence of acetone (FC) resulted in even more improved dissolution as compared to grinding with V/V mixtures of methanol and ethanol (FD and FE). This can be explained by the fact that high solubility of PCM in methanol/ethanol mixture as compare to pure acetone (solubility of PCM in methanol 371, in ethanol 232 and in acetone $111 \mathrm{mg} / \mathrm{g}$ of the solvent) resulted in solvent assisted recrystallisation as demonstrated by spottiness (loss of peak resolution i.e. preferred orientation effect) of PXRD pattern.

Release kinetics results show that the release of PCM from formulations F1 and F2 followed Korsemeyer-Peppas and Hixon- Crowell models, respectively. While dissolution data of the cocrystal formulations FA \&FB followed Korsemeyer-Peppas and formulations FC, FD \& FE followed Hixon-Crowell model for drug release (Table 4). Moreover all the formulations showed non-Fickian (anomalous) drug release $(0.45 \leq n \leq 0.89)$.

Place figure 8 here

Place Table 4 here

\section{In-Vivo performance of PCM and co-crystals}

Place figure 9 here

Powder co-crystal samples from each of the successful method showing higher IDR i.e. C and E were selected for oral bioavailability studies. Figure 9 shows the plasma concentration profiles for 
PCM and selected co-crystals. The mean pharmacokinetic metrics calculated from the sheep model study data are presented in Table 5. The mean AUC values were 11.22 and $9.36 \mu \mathrm{gh} / \mathrm{ml}$ for cocrystals $\mathrm{C}$ and E, respectively, which were almost two times enhanced that of PCM (5.02 $\mu \mathrm{gh} / \mathrm{ml})$. $\mathrm{C}_{\max }$ of $\mathrm{C}(2.40 \mu \mathrm{g} / \mathrm{ml})$ and $\mathrm{E}(1.72 \mu \mathrm{g} / \mathrm{ml})$ was 2.45 and 1.80 fold that of PCM $(0.98 \mu \mathrm{g} / \mathrm{ml})$ without any change in the time for peak concentration. The increase in peak concentration for cocrystals may be attributed to decreased elimination because of higher accumulation of drug. Mean residence time of the co-crystals was observed to be high with low clearance values suggesting enhanced absorption window. Co-crystals also showed more than two times enhancement in the relative oral bioavailability than the pure PCM. The bioavailability of both co-crystals was significantly better than pure drug based on One way ANOVA followed by Tukey's post hoc test $(p<0.05)$.

Difference in in-vivo behaviour between the co-crystal samples prepared by two methods can be attributed to the dissimilarity in the physicochemical properties especially dissolution rate (Figure 8). Physiological variations among the subjects may also contribute to these small differences. However in comparison with each other ( $\mathrm{C}$ with $\mathrm{E}$ and $\mathrm{E}$ with $\mathrm{C}$ ) the pharmacokinetic parameters $\mathrm{C}_{\max }$ and AUC were insignificant $(p>0.05)$.

Place table 5 here

\section{CONCLUSION}

PCM is a low solubility compound with poor tabletability. A co-crystal incorporating PCM and CAF was successfully developed by liquid assisted grinding and solvent evaporation. Co-crystals showed improved IDR and compressional properties. In-Vivo kinetic results from sheep model also confirmed a significant increase in the oral bioavailability of PCM. This suggests cocrystallization a useful technique to improve the compressional, physicochemical and pharmacokinetic properties of PCM and proving caffeine a suitable co-former.

\section{ACKNOWLEDGEMENTS:}

Authors would like to acknowledge Higher Education Commission of Pakistan for providing funding under NRPU programme to University College of Pharmacy, University of the Punjab. 
We would also like to thank Mr. Abdul Muqeet Khan from University of Veterinary and Animal Sciences for helping in pharmacokinetic analysis.

\section{DECLARATION OF INTEREST:}

Authors report no conflict of interest.

\section{REFERENCES}

1. Aakeröy CB, Salmon DJ. Building co-crystals with molecular sense and supramolecular sensibility. CrystEngComm 2005;7:439-48.

2. Childs SL, Zaworotko MJ. The reemergence of cocrystals: the crystal clear writing is on the wall introduction to virtual special issue on pharmaceutical cocrystals. Cryst Growth Des 2009;9:4208-11.

3. Henck J-O, Byrn SR. Designing a molecular delivery system within a preclinical timeframe. Drug Discovery Today 2007;12:189-99.

4. Friščić $T$, Jones $W$. Benefits of cocrystallisation in pharmaceutical materials science: an update. J Pharm Pharmcol 2010;62:1547-59.

5. Banerjee R, Bhatt PM, Ravindra NV, et al. Saccharin salts of active pharmaceutical ingredients, their crystal structures, and increased water solubilities. Cryst Growth Des 2005;5:2299-309.

6. Good DJ, Rodríguez-Hornedo Nr. Solubility advantage of pharmaceutical cocrystals. Cryst Growth Des 2009;9:2252-64.

7. Khadka P, Ro J, Kim H, et al. Pharmaceutical particle technologies: An approach to improve drug solubility, dissolution and bioavailability. Asian J Pharm Sci 2014;9:304-16.

8. Agharkar S, Lindenbaum S, Higuchi T. Enhancement of solubility of drug salts by hydrophilic counterions: properties of organic salts of an antimalarial drug. J Pharm Sci 1976;65:747-49.

9. Torchilin VP. Micellar nanocarriers: pharmaceutical perspectives. Pharm Res 2007;24:1-16.

10. Rajewski RA, Stella VJ. Pharmaceutical applications of cyclodextrins. 2. In vivo drug delivery. J Pharm Sci 1996;85:1142-69.

11. Humberstone AJ, Charman WN. Lipid-based vehicles for the oral delivery of poorly water soluble drugs. Adv Drug Deliv Rev 1997;25:103-28.

12. Datta S, Grant DJ. Crystal structures of drugs: advances in determination, prediction and engineering. Nat Rev Drug Discov 2004;3:42-57.

13. Blagden N, De Matas M, Gavan P, et al. Crystal engineering of active pharmaceutical ingredients to improve solubility and dissolution rates. Adv Drug Deliv Rev 2007;59:617-30.

14. Desiraju GR. Chemistry beyond the molecule. Nature 2001;412:397-400.

15. Desiraju GR. Crystal engineering: A brief overview. J Chem Sci 2010;122:667-75.

16. Gao Y, Gao J, Liu Z, et al. Coformer selection based on degradation pathway of drugs: a case study of adefovir dipivoxil-saccharin and adefovir dipivoxil-nicotinamide cocrystals. Int J Pharm 2012;438:327-35.

17. Vangala VR, Chow PS, Tan RB. Characterization, physicochemical and photo-stability of a cocrystal involving an antibiotic drug, nitrofurantoin, and 4-hydroxybenzoic acid. CrystEngComm 2011;13:759-62.

18. Liu X, Lu M, Guo Z, Huang L, et al. Improving the chemical stability of amorphous solid dispersion with cocrystal technique by hot melt extrusion. Pharm Res. 2012;29:806-17. 
19. Perumalla SR, Sun CC. Improved solid-state stability of salts by cocrystallization between conjugate acid-base pairs. CrystEngComm 2013;15:5756-59.

20. McNamara DP, Childs SL, Giordano J, et al. Use of a glutaric acid cocrystal to improve oral bioavailability of a low solubility API. Pharm Res 2006;23:1888-97.

21. Ullah M, Hussain I, Sun CC. The development of carbamazepine-succinic acid cocrystal Tablet formulations with improved in vitro and in vivo performance. Drug Dev Ind Pharm 2016;42:96976.

22. Sun CC, Hou H. Improving mechanical properties of caffeine and methyl gallate crystals by cocrystallization. Cryst Growth Des 2008;8:1575-79.

23. Maeno Y, Fukami T, Kawahata M, et al. Novel pharmaceutical cocrystal consisting of paracetamol and trimethylglycine, a new promising cocrystal former. Int J Pharm 2014;473:17986.

24. Karki S, Friščić T, Fábián L, et al. Improving mechanical properties of crystalline solids by cocrystal formation: new compressible forms of paracetamol. Adv Mater 2009;21:3905-9.

25. Fleischman SG, Kuduva SS, McMahon JA, et al. Crystal engineering of the composition of pharmaceutical phases: multiple-component crystalline solids involving carbamazepine. Cryst Growth Des 2003;3:909-19.

26. Arora KK, Zaworotko MJ. Pharmaceutical co-crystals: A new opportunity in pharmaceutical science for a long-known but little studied class of compounds. Polymorphism in pharmaceutical solids. 2009;2:281-313.

27. Vishweshwar P, Mcmahon JA, Bis JA, et al. Pharmaceutical co-crystals. J Pharm Sci 2006;95:499516.

28. Thakuria R, Delori A, Jones W, et al. Pharmaceutical cocrystals and poorly soluble drugs. Int J Pharm 2013;453:101-25.

29. Huskić I, Christopherson JC, Užarević K, et al. In situ monitoring of vapour-induced assembly of pharmaceutical cocrystals using a benchtop powder X-ray diffractometer. Chem Comm. 2016;52:5120-3.

30. Di Martino P, Guyot-Hermann A, Conflant $P$, et al. A new pure paracetamol for direct compression: the orthorhombic form. Int J Pharm 1996;128:1-8.

31. Rasenack N, Müller BW. Crystal habit and Tableting behavior. Int J Pharm 2002;244:45-57.

32. Lonare AA, Patel SR. Antisolvent crystallization of poorly water soluble drugs. Int J Chem Eng Appl 2013;4:337-41.

33. Healy A, McCarthy L, Gallagher K, et al. Sensitivity of dissolution rate to location in the paddle dissolution apparatus. J Pharm Pharmcol 2002;54:441-4.

34. Nicklasson M, Brodin A, Nyqvist $\mathrm{H}$. Studies on the relationship between solubility and intrinsic rate of dissolution as a function of pH. Acta pharm suec 1981;18:119-28.

35. Heckel R. Density-pressure relationships in powder compaction. Trans Metall Soc AIME 1961;221:671-5.

36. Hersey J, Rees J. Deformation of particles during briquetting. Nature 1971;230:96-96.

37. Fell J, Newton J. Determination of Tablet strength by the diametral-compression test. J Pharm Sci 1970;59:688-91.

38. Zhang $\mathrm{Y}$, Huo M, Zhou J, et al. DDSolver: an add-in program for modeling and comparison of drug dissolution profiles. AAPS J 2010;12:263-71.

39. Alswayeh R, Alvi SN, Hammami MM. Rapid determination of acetaminophen levels in humans plasma by high performance liquid chromatography. Am J PharmTech Res 2016;6:710-9.

40. Zhang Y, Huo M, Zhou J, et al. PKSolver: An add-in program for pharmacokinetic and pharmacodynamic data analysis in Microsoft Excel. Comput Methods Programs Biomed 2010;99:306-14. 
41. Haisa M, Kashino S, Maeda $\mathrm{H}$. The orthorhombic form of $\mathrm{p}$-hydroxyacetanilide. Acta Crystallogr SecB 1974;30:2510-2.

42. Shiraki K, Takata N, Takano R, et al. Dissolution improvement and the mechanism of the improvement from cocrystallization of poorly water-soluble compounds. Pharm Res 2008;25:2581-92.

43. Sun CC. Cocrystallization for successful drug delivery. Expert Opin Drug Deliv 2013;10:201-13.

44. Adetunji OA, Odeniyi MA, Itiola OA. Compression, mechanical and release properties of chloroquine phosphate Tablets containing corn and trifoliate yam starches as binders. Trop J PharmRes 2006;5:589-96. 
Table 1. Screening of Co-crystals by using various methods ("+ " represents formation of co-crystals, characterized by DSC and PXRD results, “" "represents re-crystallization of starting material or no crystallization) (co-crystals from successful techniques are coded A, B, C, D \& E as shown in Table 1)

\begin{tabular}{|c|c|c|c|c|}
\hline Method Used & Solvent Used & $\begin{array}{l}\text { Solvent } \\
\text { ratio }\end{array}$ & $\begin{array}{l}\text { Wt ratio of } \\
\text { PCM/CAF }\end{array}$ & $\begin{array}{c}\text { Observations } \\
\text { (co-crystal } \\
\text { formation) }\end{array}$ \\
\hline \multirow{3}{*}{$\begin{array}{l}\text { Neat (dry) } \\
\text { grinding }\end{array}$} & \multirow{3}{*}{ N/A } & & $1: 1$ & - \\
\hline & & & $1: 2$ & - \\
\hline & & & $2: 1$ & - \\
\hline \multirow{9}{*}{$\begin{array}{l}\text { Liquid assisted } \\
\text { grinding }\end{array}$} & \multirow{6}{*}{$\mathrm{MeOH}: \mathrm{EtOH}$} & \multirow{3}{*}{$1: 1(\mathrm{~S} 1)$} & $1: 1$ & $+(\mathrm{A})$ \\
\hline & & & $1: 2$ & - \\
\hline & & & $2: 1$ & - \\
\hline & & \multirow{3}{*}{ 1:2 (S2) } & $1: 1$ & $+(\mathrm{B})$ \\
\hline & & & $1: 2$ & - \\
\hline & & & $2: 1$ & - \\
\hline & \multirow{3}{*}{ Acetone } & \multirow{3}{*}{$\begin{array}{l}\text { Alone } \\
\text { (S3) }\end{array}$} & $1: 1$ & $+(\mathrm{C})$ \\
\hline & & & $1: 2$ & - \\
\hline & & & $2: 1$ & - \\
\hline \multirow{15}{*}{$\begin{array}{l}\text { Solvent } \\
\text { evaporation }\end{array}$} & \multirow{6}{*}{$\mathrm{MeOH}: \mathrm{EtOH}$} & \multirow{3}{*}{$1: 1(\mathrm{~S} 1)$} & $1: 1$ & - \\
\hline & & & $1: 2$ & - \\
\hline & & & $2: 1$ & $+(\mathrm{D})$ \\
\hline & & \multirow{3}{*}{$1: 2(\mathrm{~S} 2)$} & $1: 1$ & - \\
\hline & & & $1: 2$ & - \\
\hline & & & $2: 1$ & $+(\mathrm{E})$ \\
\hline & \multirow{3}{*}{ Acetone } & \multirow{3}{*}{$\begin{array}{l}\text { Alone } \\
\text { (S3) }\end{array}$} & $1: 1$ & - \\
\hline & & & $1: 2$ & - \\
\hline & & & $2: 1$ & - \\
\hline & \multirow{6}{*}{$\mathrm{H} 2 \mathrm{O}: \mathrm{EtOH}$} & & $1: 1$ & - \\
\hline & & $1: 1(\mathrm{~S} 4)$ & $1: 2$ & - \\
\hline & & & $2: 1$ & - \\
\hline & & & $1: 1$ & - \\
\hline & & $1: 2$ (S5) & $1: 2$ & - \\
\hline & & & $2: 1$ & - \\
\hline \multirow{3}{*}{ Anti-Solvent } & Solvents: $\mathrm{MeOH} \&$ & & $1: 1$ & - \\
\hline & Acetone & & $1: 2$ & - \\
\hline & Anti- solvent: Water & & $2: 1$ & - \\
\hline
\end{tabular}


Table 2: Onset, mid and off set temperatures of DSC thermograms of PCM, CAF and PCM-CAF Co-crystals *(A, B, $\mathrm{C}, \mathrm{D}$ and $\mathrm{E}$ are codes given to co-crystals prepared by successful methods as shown in Table 1).

\begin{tabular}{|c|c|c|c|}
\hline Material & Onset temperature & Mid temperature & Offset temperature \\
\hline PCM & 165.59 & 172.37 & 204.20 \\
\hline CAF Form I & 216.99 & 231.08 & 247.45 \\
\hline Form II & 146.49 & 160.33 & 175.91 \\
\hline A & 130.31 & 141.02 & 156.57 \\
\hline B & 128.21 & 140.92 & 174.19 \\
\hline $\mathrm{C}$ & 131.93 & 142.5 & 165.87 \\
\hline $\mathrm{D}$ & 133.58 & 160.92 & 194.16 \\
\hline E & 133.58 & 148.68 & 172.51 \\
\hline
\end{tabular}

Table 3. Physical and mechanical properties of tablet formulations prepared from pure PCM (direct compression (F1) and wet granulation (F2)) and PCM-CAF Co-crystals.*Mean yield pressure values were derived from Heckle plots only from pure PCM and PCM-CAF co-crystals powders.

\begin{tabular}{|c|c|c|c|c|c|c|c|}
\hline Properties & F1 & F2 & FA & FB & FC & FD & FE \\
\hline $\begin{array}{l}\text { Tablet } \\
\text { diameter(mm) }\end{array}$ & $13 \pm 0.01$ & $13 \pm 0.01$ & $13 \pm 0.01$ & $13 \pm 0.01$ & $13 \pm 0.01$ & $13 \pm 0.01$ & $13 \pm 0.01$ \\
\hline $\begin{array}{l}\text { Breaking } \\
\text { force }(\mathrm{N})\end{array}$ & $18 \pm 1.0$ & $66 \pm 1.0$ & $270 \pm 5$ & $285 \pm 5$ & $309 \pm 5$ & $90 \pm 2.5$ & $94 \pm 2.5$ \\
\hline $\begin{array}{l}\text { Tensile } \\
\text { strength(MPa) }\end{array}$ & $\begin{array}{c}0.52 \pm \\
0.01\end{array}$ & $1.90 \pm 0.01$ & $3.48 \pm 0.01$ & $3.67 \pm 0.01$ & $3.98 \pm 0.01$ & $1.82 \pm 0.01$ & $1.88 \pm 0.01$ \\
\hline $\begin{array}{l}\text { Disintegration } \\
\text { time(min) }\end{array}$ & $1 \pm 0.5$ & $0.67 \pm 0.5$ & $8.0 \pm 0.5$ & $7.5 \pm 0.5$ & $7.5 \pm 0.5$ & $5 \pm 0.5$ & $5 \pm 0.5$ \\
\hline $\begin{array}{l}\text { *Mean yield } \\
\text { pressure }(\mathrm{MPa})\end{array}$ & & .33 & 33.03 & 80 & 28.65 & 33.03 & 47.62 \\
\hline
\end{tabular}


Table 4: Drug release kinetics from various formulations of PCM and PCM-CAF co-crystals

\begin{tabular}{lcccccccc}
\hline Release kinetics & & F1 & F2 & FA & FB & FC & FD & FE \\
Zero order & $\mathrm{R}^{2}$ & 0.9847 & 0.8559 & 0.7634 & 0.7383 & 0.5443 & 0.8172 & 0.7257 \\
First order & $\mathrm{R}^{2}$ & 0.9821 & 0.9628 & 0.9693 & 0.9575 & 0.9531 & 0.9368 & 0.9688 \\
Higuchi model & $\mathrm{R}^{2}$ & 0.8926 & 0.9148 & 0.9340 & 0.9053 & 0.8891 & 0.8834 & 0.9327 \\
$\begin{array}{l}\text { Hixon- Crowell } \\
\text { model }\end{array}$ & $\mathrm{R}^{2}$ & 0.9904 & 0.9764 & 0.9775 & 0.9594 & 0.9712 & 0.9517 & 0.9810 \\
$\begin{array}{l}\text { Korsemeyer-Peppas } \\
\text { model }\end{array}$ & $\mathrm{R}^{2}$ & 0.9926 & 0.9421 & 0.9843 & 0.9791 & 0.9230 & 0.9077 & 0.9340 \\
& $\mathrm{n}$ & 0.873 & 0.659 & 0.758 & 0.751 & 0.549 & 0.650 & 0.531 \\
\hline
\end{tabular}

Table 5. Pharmacokinetic parameters of PCM and PCM-CAF Co-crystals in sheep, obtained after single oral administration at a dose of $30 \mathrm{mg} / \mathrm{Kg}$ body weight $(\mathrm{n}=6)$. *R.B relative to PCM

\begin{tabular}{lccc}
\hline Parameters & PCM & $\mathbf{C}$ & E \\
& Mean $\pm \mathrm{SD}$ & Mean $\pm \mathrm{SD}$ & Mean $\pm \mathrm{SD}$ \\
\hline $\mathrm{C}_{\max }(\mu \mathrm{g} / \mathrm{ml})$ & $0.98 \pm 0.18$ & $2.40 \pm 0.51$ & $1.72 \pm 0.66$ \\
$\mathrm{~T}_{\max }(\mathrm{h})$ & $1.67 \pm 0.25$ & $1.67 \pm 0.25$ & $1.67 \pm 0.25$ \\
$\mathrm{AUC}_{\mathrm{O}-10 \mathrm{~h}}(\mu \mathrm{gh} / \mathrm{ml})$ & $5.02 \pm 1.3$ & $11.22 \pm 1.67$ & $9.36 \pm 1.60$ \\
$\mathrm{AUC}_{\mathrm{O}-\infty}(\mu \mathrm{gh} / \mathrm{ml})$ & $5.25 \pm 0.5$ & $13.01 \pm 1.22$ & $10.44 \pm 1.93$ \\
$\mathrm{AUMC}$ & $-\infty(\mu \mathrm{gh} / \mathrm{ml})$ & $72.46 \pm 14.84$ & $53.64 \pm 10.54$ \\
$\mathrm{MRT}(\mathrm{h})$ & $21.86 \pm 05.19$ & $5.52 \pm 1.07$ & $5.13 \pm 0.79$ \\
$\mathrm{Kel}\left(\mathrm{h}^{-1}\right)$ & $3.86 \pm 0.87$ & $0.26 \pm 0.13$ & $0.27 \pm 0.03$ \\
$\mathrm{~T}_{1 / 2}(\mathrm{~h})$ & $0.33 \pm 0.15$ & $3.29 \pm 1.75$ & $2.53 \pm 0.38$ \\
$\mathrm{CL} / \mathrm{F}(\mu \mathrm{g} / \mathrm{ml}) / \mathrm{h}$ & $1.36 \pm 0.41$ & $56.45 \pm 4.48$ & $75.27 \pm 14.49$ \\
$\mathrm{Vd} / \mathrm{F}(\mu \mathrm{g} / \mathrm{ml})$ & $161.48 \pm 19.01$ & $264.83 \pm 26.78$ & $276.72 \pm 19.19$ \\
$* \mathrm{Relative} \mathrm{bioavailability}$ & $294.18 \pm 28.33$ & 2.47 & 1.98 \\
$(\mathrm{R} . \mathrm{B})$ & & & \\
\hline
\end{tabular}


<smiles>CC(=O)Nc1ccc(O)cc1</smiles><smiles>Cn1c(=O)c2c(ncn2C)n(C)c1=O</smiles>

Figure 1. Molecular structures of Paracetamol (left) and Caffeine (right)

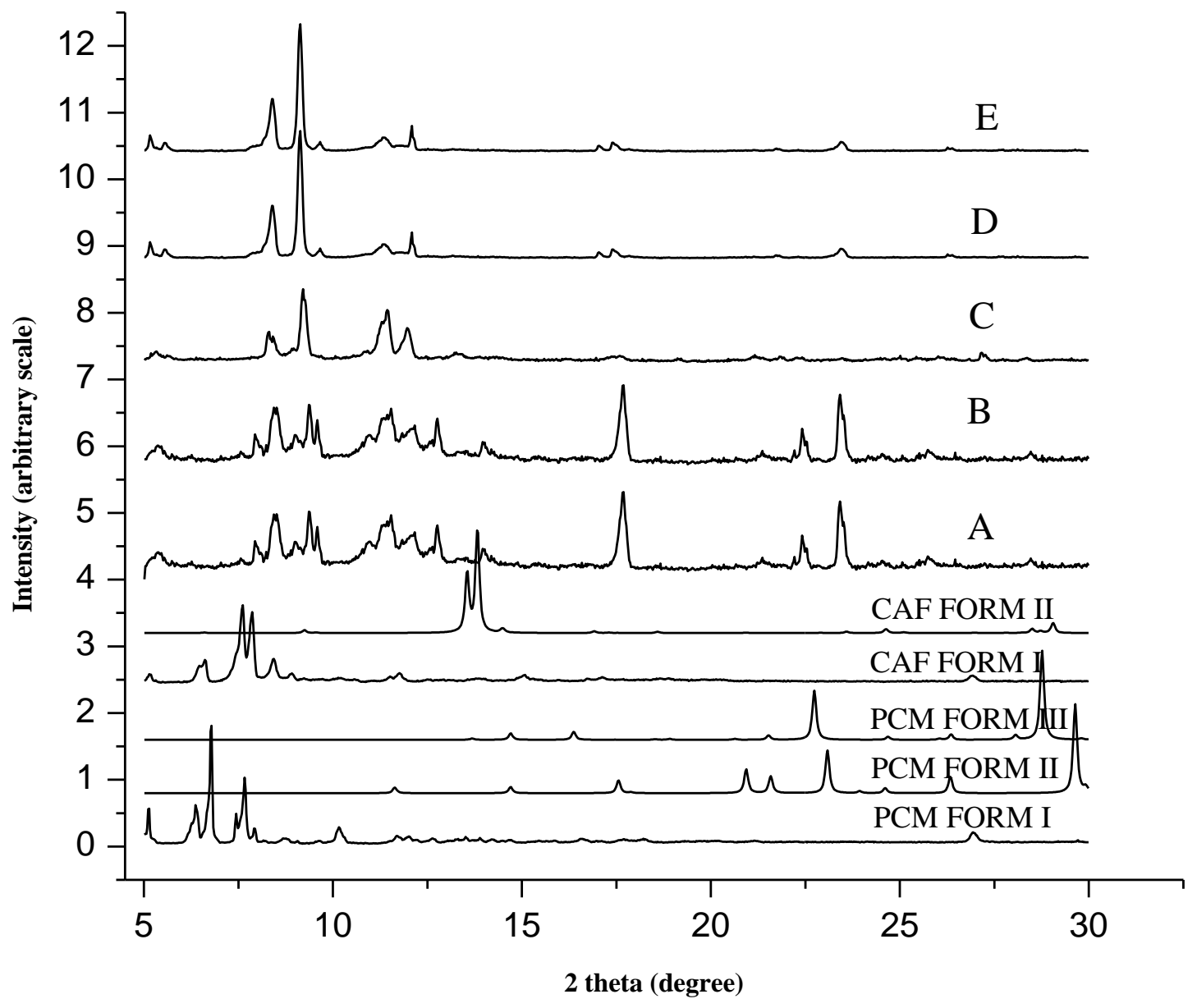

Figure 2. PXRD patterns of PCM, CAF and PCM-CAF Co-crystals 


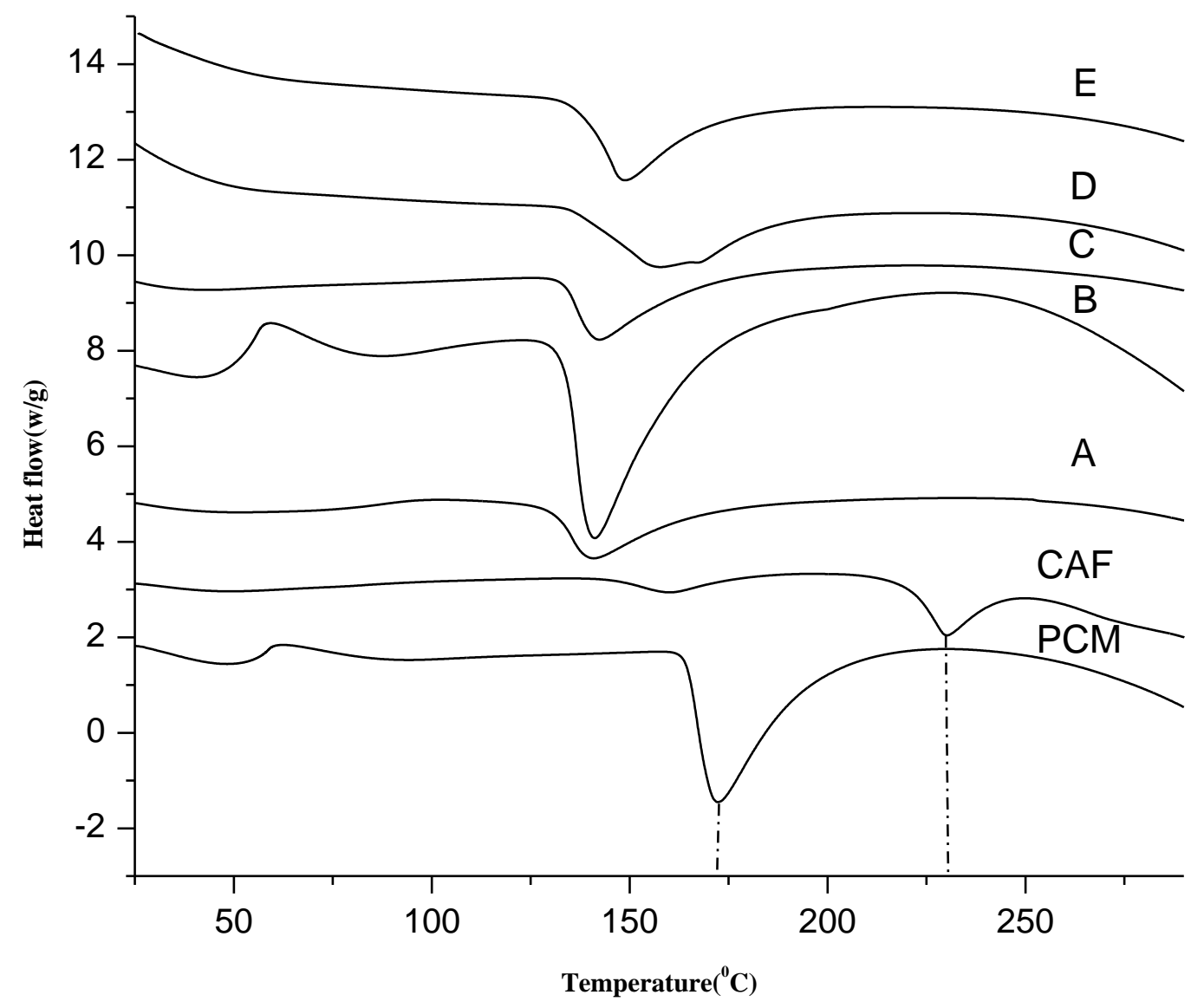

Figure 3. DSC thermograms of PCM, CAF and PCM-CAF Co-crystals 


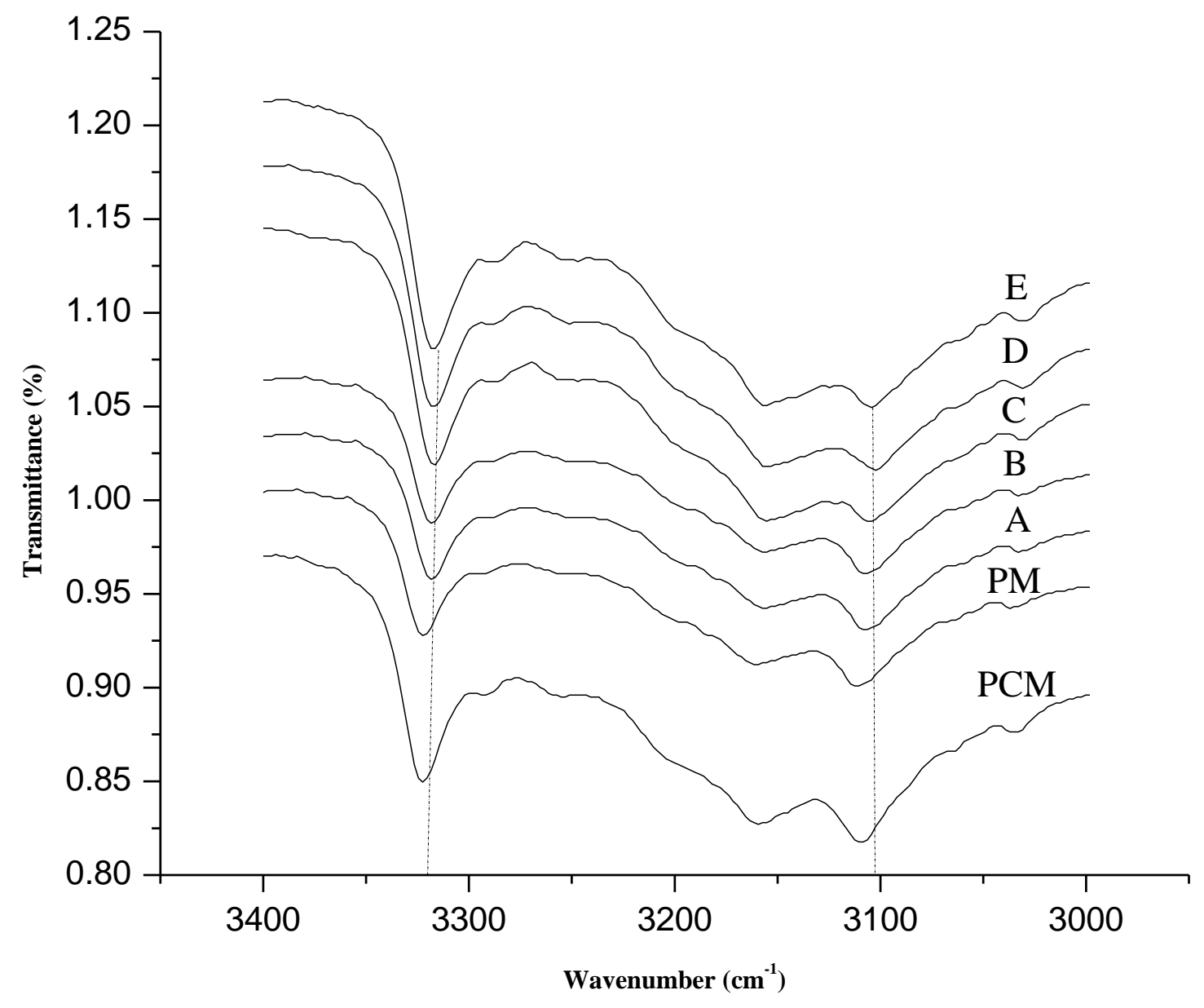

Figure 4. ATR-FTIR spectra of PCM, PM and PCM-CAF Co-crystals highlighting the N-H amide stretch and phenolic $\mathrm{OH}$ stretch regions for PCM 


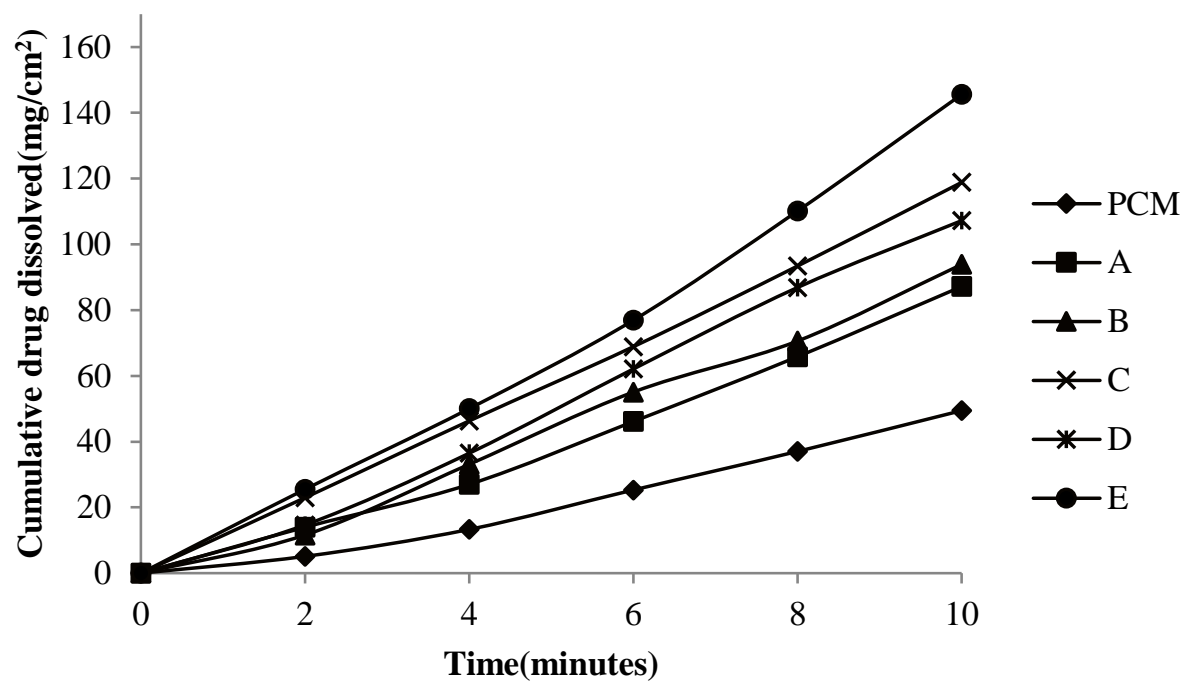

Figure 5. Intrinsic dissolution profiles of PCM alone and from Co-crystals in phosphate buffer pH 6.8 at $37^{\circ} \mathrm{C}$
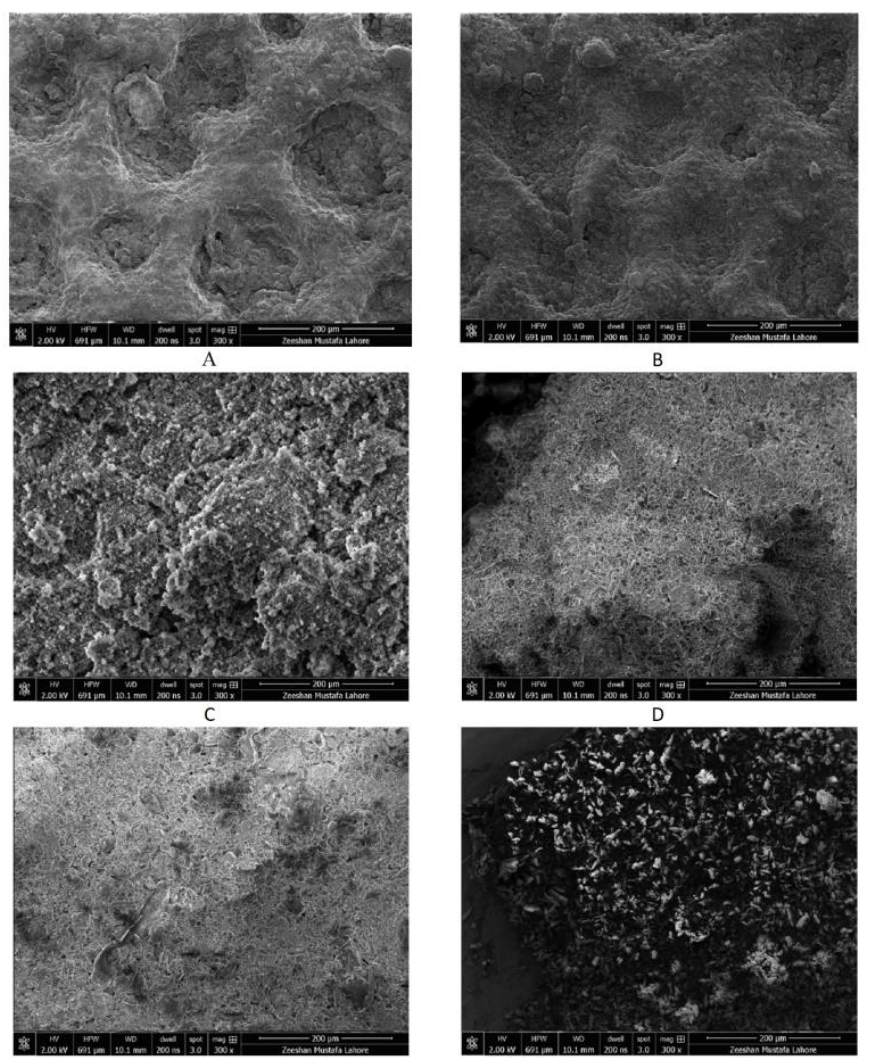

Figure 6: SEM images of pure PCM and PCM-CAF Co-crystals 


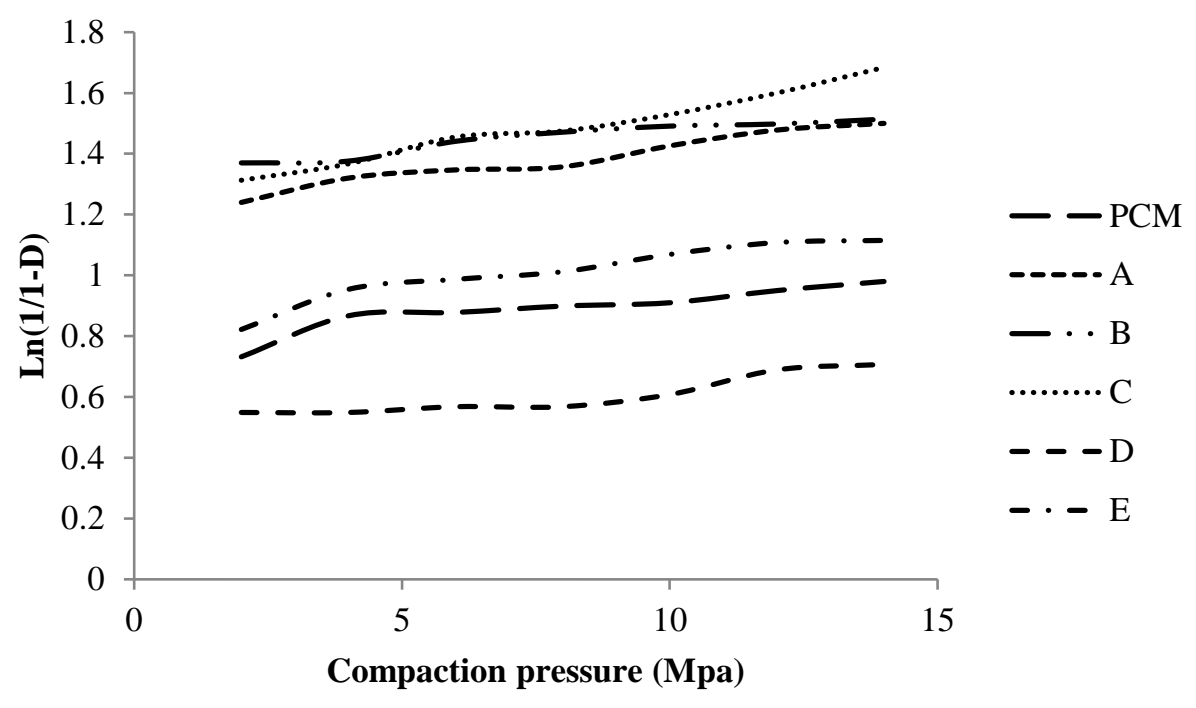

Figure 7. Heckle plots for PCM and PCM-CAF Co-crystals

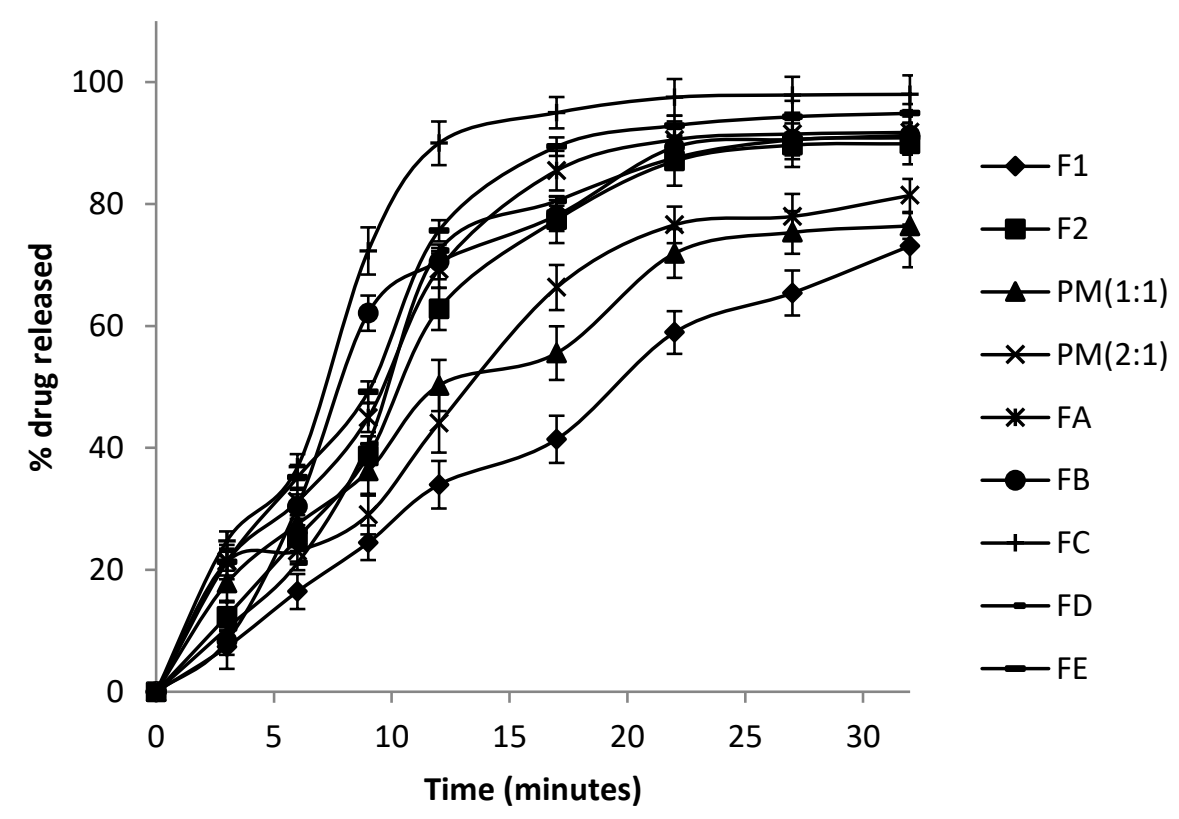

Figure 8. In Vitro drug release comparison of various formulations of PCM, PCM-CAF co-crystals and physical mixtures $(n=3)$. 


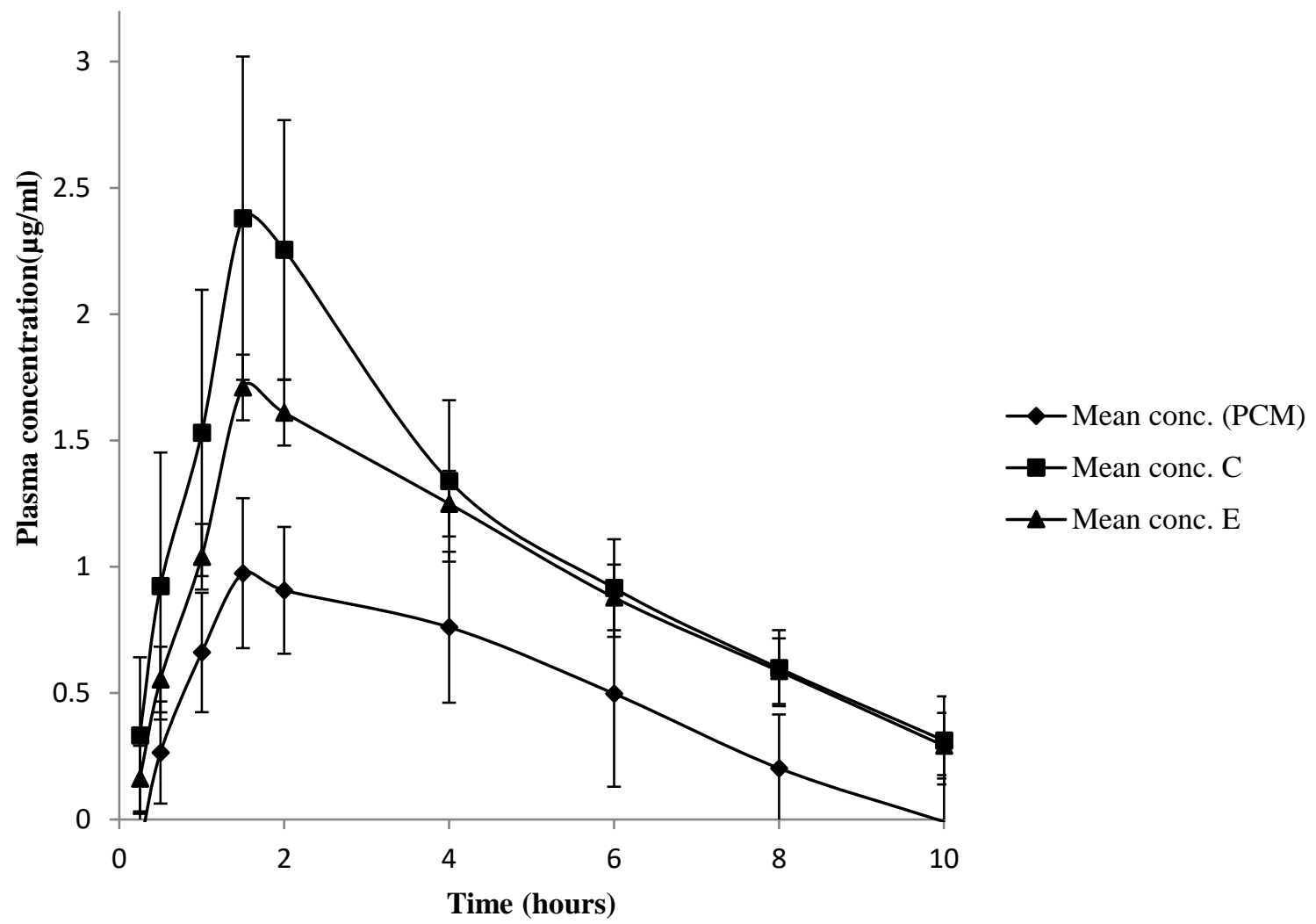

Figure 9: Sheep plasma concentration with time for PCM and PCM-CAF Co-crystals 